\title{
Density Variation of Different Shaped Food Particulates in Fluid Bed Drying: Empirical Models
}

\author{
Wiji Senadeera* \\ School of Engineering Systems, Queensland University of Technology \\ GPO Box 2434, Brisbane, QLD, 4001, Australia \\ تباين كتافة جسيمات المواد الغذائية باختلاف أشكالها عند \\ التجفيف: النماذج التجريبية \\ ويجي سيناديرا

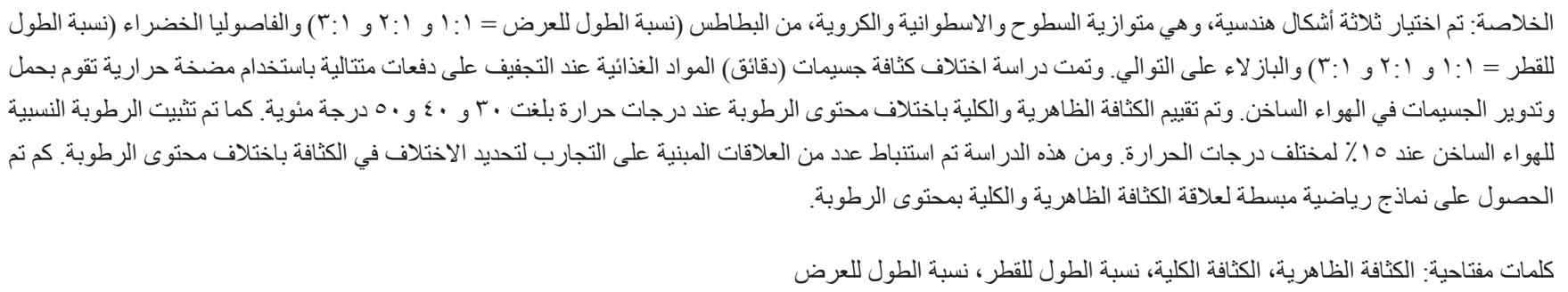

ABSTRACT: Three particular geometrical shapes, parallelepiped, cylindrical and spherical, were selected from potatoes (aspect ratio $=1: 1$, $2: 1,3: 1$ ), cut beans (length:diameter $=1: 1,2: 1,3: 1$ ) and peas respectively. The density variation of food particulates was studied in a batch fluidised bed dryer connected to a heat pump dehumidifier system. Apparent density and bulk density were evaluated with non-dimensional moisture at three different drying temperatures of 30,40 and $50{ }^{\circ} \mathrm{C}$. Relative humidity of hot air was kept at $15 \%$ in all drying temperatures. Several empirical relationships were developed for the determination of changes in densities with the moisture content. Simple mathematical models were obtained to relate apparent density and bulk density with moisture content.

Keywords: apparent density, bulk density, length diameter ratio, aspect ratio.

\section{Introduction}

Drying is a major food processing operation in the food industry, which consumes large amounts of energy. It is a very complex process and involves mass and heat transfer processes simultaneously. The quality of food materials during drying depends not only on the initial quality of the raw materials, but also on the processing conditions during drying (Karel, 1991). The fluidized bed drying has been recognized as a gentle and uniform drying with a high degree of efficiency (Senadeera et al., 1998). This is a very convenient method for heat-sensitive food materials as it is relatively fast, and thermal damages can be reduced (Gibert et al., 1980, Giner and Calvelo, 1987).

In the process of drying, several physical and structural changes are occurring simultaneously. Most of the natural food particulates for human/animal consumption are available as high moisture materials, and drying could be used to reduce the moisture content in order to avoid the microbial growth (Fusco et al., 1991). Natural food particles are available in different irregular shapes and sizes. During drying, shape and size of the products change appreciably, influencing their particle properties inside the drying equipment (Ratti, 1994).
Bulk density and particle density are important physical properties in food materials, which influence final texture, quality and transport properties of the dry foods. Bulk density and particle density are the main parameters in designing equipment for the food particulates. Bulk density and porosity are related to flow resistance through beds, food storage and packaging of the products (Madamba et al., 1994). Particle density is important in heat transfer of the material. Density models are empirical relations based on experimental observations: however, theoretical models are based on mass and volume (Rahman and Driscoll, 1994).

The effect of drying methods on bulk density and particle density of banana, apple, carrot and potato were studied and simple mathematical models were correlated with moisture (Krokida and Maroulis, 1997). Density models were developed for garlic (Madamba et al., 1994) and for apple, carrot and potato cubes (Zogzas et al., 1994). Density models were developed for squid flesh during air drying (Rahman and Potluri, 1990). The effect of drying condition was assessed and models were developed for peas during air drying (Medeiros and Sereno, 1994). Change in structure, 
density and porosity of potato during drying have also been studied (Wang and Brennan, 1995).

The objective of this study was to investigate the change of density for different shaped food materials with varying dimensional moisture ratios and to relate these changes to moisture content using suitable models. Fluidized bed drying experiments were undertaken for an initial bed height of $150 \mathrm{~mm}$ in a flexi-glass laboratory batch fluid bed unit connected to a heat pump system.

\section{Materials and Methods}

\section{Material Preparation}

Fresh green beans Phaseolus vulgaris of Labrador variety were used for producing cylindrical particles. Beans were purchased from the same supplier to maximize reproducibility of the experimental results. When selecting the size of beans, care was taken to obtain batches of consistent diameter of $10 \pm 1 \mathrm{~mm}$. Size was measured using vernier callipers with an accuracy of 0.05 $\mathrm{mm}$. Both ends of the beans were removed and only the middle portions, which resemble a cylindrical shape, were used to produce the required samples. Samples were prepared in three lengths to diameter ratios of 1:1,2:1 and $3: 1$, respectively. After preparation, beans were kept in a plastic container in a cold room at $4^{0} \mathrm{C}$ for more than 24 hours in order to make uniform moisture distribution.

Potatoes, Solanum tuberosum, of the variety Sebago were purchased from the same supplier in $50 \mathrm{~kg}$ bags. Before sample preparation, potatoes were washed and brushed to remove skin and mud. First, large cuboid shapes were cut from the whole potatoes, removing the outer portions near the skin. Subsequently, those cubes were cut carefully using a sharp knife to produce parallelepipeds with a square cross-section and sides $6.5 \mathrm{~mm}$ wide. Those slices were then pushed through a stainless steel square cutter to make parallelepipeds in a dicing machine (Hobart, Australia), by incorporating a cutter which makes $6.5 \mathrm{~mm} \times 6.5 \mathrm{~mm}$ square cross-section. In the case of aspect ratio of $1: 1$, the potato cubes were pushed through the same cutter and axial length was controlled to a length of $6.5 \mathrm{~mm}$ by a cutting blade. According to the required aspect ratios of $3: 1,2: 1$ and $1: 1$, the particles were cut carefully to lengths of $19.5,13$ and $6.5 \mathrm{~mm}$, respectively. Immediately after cutting, all the samples were immersed in a sodium metabisulphite solution $(0.1 \% \mathrm{w} / \mathrm{w})$ for 15 minutes to prevent browning during drying. The samples were drained on a mesh tray. Then samples were placed in a plastic bag and kept in a cold room for 24 hours at $4^{\circ}$ $\mathrm{C}$ in order to produce uniform moisture distribution within the sample.

For the spherical model, fresh green peas, Pisum sativum of Bounty variety, were purchased from the same supplier in $10 \mathrm{~kg}$ boxes in their pods. They were shelled by hand and graded using a wire mesh. Those with average diameter $10 \pm 1 \mathrm{~mm}$ were selected and stored in a cold room for 24 hours at $4^{\circ} \mathrm{C}$ in order to produce uniform moisture distribution.

\section{Experimental Design}

Three batches were prepared at once and used for three drying temperatures. Two replicate batches were prepared for cut beans ( $3 \mathrm{~L}: \mathrm{D}$ ratios) and diced potato (3 aspect ratios). Three replicate batches were prepared for peas. For beans and potato, a split unit design - with two replications corresponding to processing time, with three sizes per block and three drying temperatures for each size - was used. For peas, a randomized complete block design with three replications for each temperature was used.

For each particulate size, one batch stored in the cold room was taken for fluidised bed drying experimentation. The fluidised bed dryer was connected to a heat pump dehumidifier system (Figure 1). A schematic diagram of the connection arrangement is shown in Figure 2. The drying conditions of 30,40 and $50^{\circ} \mathrm{C}$ were set by the temperature controller in the heat pump dehumidifier system, and the drying setup was run for 2 hours to achieve steady state conditions of drying before material introduction. The relative humidity during drying was maintained at $15 \%$. Initial bed height of $150 \mathrm{~mm}$ was used for all materials to ensure enough material was available for sample collection and subsequent drying during the entire drying period. The hot air velocity passing through the material bed was kept constant at $2.2 \mathrm{~m} / \mathrm{s}$ for all drying experiments. This velocity was selected because it was within the limit of fluidisation and terminal velocity of all

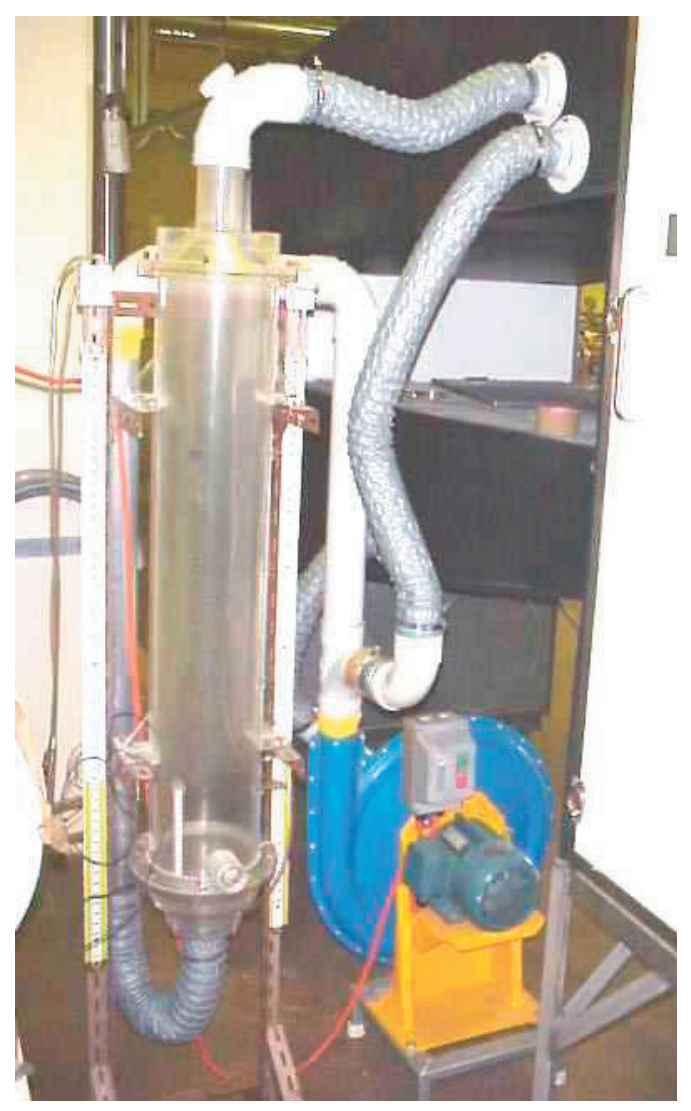

Figure 1. Fluidised bed drying experimental setup. 


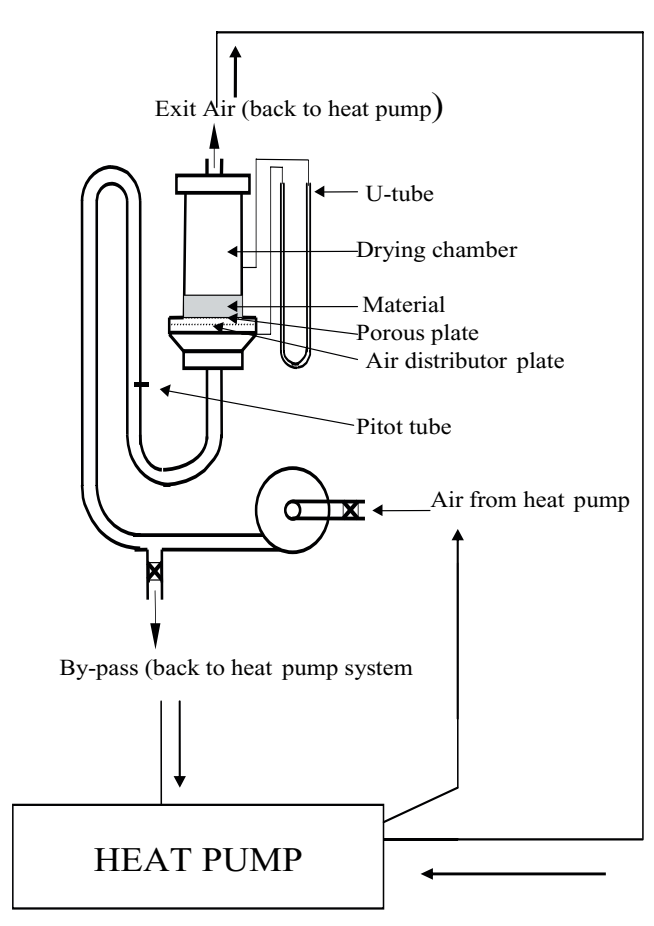

Figure 2. Schematic of the fluidised bed drying setup.

three materials and within the capability of the fan. The air-flow entering the dryer was controlled by flow control valves. Samples were collected from the dryer at 30 minute intervals through the sample outlet. Each time they were collected in a sealable container and immediately used for moisture determination and volume measurements.

The volume of the particles was measured by the liquid displacement method using liquid paraffin $(\mathrm{SG}=0.8787$ at $30^{\circ} \mathrm{C}$ ) as the medium. A measuring cylinder of $22 \mathrm{~mm}$ inside diameter and $50 \mathrm{ml}$ capacity was used for liquid displacement (Zogsas, 1994). Paraffin was employed as it does not interact with the constituents of the sample and it has a low enough density to ensure complete submergence of the particles. For one measurement, a known number of particles were immersed in paraffin. The number of particles for volume determination was increased progressively as drying progressed in order to maintain an approximately constant volume for each sample. Volume was measured by the difference of meniscus levels before and after immersion, using vernier calipers (accuracy 0.05 $\mathrm{mm}$ ). Considering the high viscosity of paraffin, care was taken to avoid formation of air bubbles and adherence of liquid to the glass walls of the cylinder above the liquid meniscus by gently dipping the samples into the liquid. An average of three readings was recorded from three replicate samples. All the measurements were taken within a minute to avoid any possibility of absorption of paraffin into the product.

The vacuum oven was used to measure the moisture content of the particles according to the AOAC method
934.06 (1995). Weighing dishes made of aluminium, 60$80 \mathrm{~mm}$ diameter and $25 \mathrm{~mm}$ deep with easily removable lids were pre-washed, dried and kept in a desiccator with silica gel for two days prior to experimentation. Duplicated samples of 5-10 g in mass weighed by an electronic balance (Sartorius, $\pm 0.001 \mathrm{~g}$ ) were thoroughly homogenised and put into tared weighing dishes from the desiccator, and placed inside a vacuum oven. The metal dishes containing the samples were in direct contact with the metal shelf of the oven. Moisture content was determined by measuring the loss in weight of finely chopped samples held at $70^{\circ} \mathrm{C}$ and $13.3 \mathrm{kPa}$ vacuum for more than 24 hours. Samples were transferred from the vacuum oven to a dessicator for cooling. The cooled, samples were weighed as quickly as possible to an accuracy of $0.1 \mathrm{mg}$.

\section{Analysis of Experimental Data}

The data were analysed by ANOVA to evaluate significant differences and both linear regression and non-linear regression to obtain suitable models. Statistical Analysis System software (SAS, 1985) was used. The experimental data on shrinkage and drying were analysed for significance (ANOVA) using the SAS routine GLM (general linear models), and the model parameters were estimated using SAS least squares routine (GLM for linear models and NLIN for non-linear models). The curve which best fitted the data was taken as the model. Model validity was tested using the coefficient of regression $\left(\mathrm{R}^{2}\right)$ and Mean Absolute Error Percentage (MAE\%).

$$
\begin{gathered}
\mathrm{R}^{2}=1-\frac{\text { residual sum of squares }}{\text { corrected total sum of squares }} \\
\mathrm{MAE} \%=\frac{100}{\mathrm{n}} \sum \frac{\mid \text { predicted value - observed value } \mid}{\mid \text { observed value } \mid}
\end{gathered}
$$

\section{Results and Discussion}

\section{Particle Density (apparent)}

The model was fitted using a non linear procedure NLIN (SAS, 1985) similar to Lozano et al. (1994):

$$
\rho_{\mathrm{ap}}=\mathrm{a}+\mathrm{b} \mathrm{MR}+\mathrm{c} \exp (-\mathrm{d} M R)
$$

where, $\rho_{\text {ap }}$ is particle density $(\mathrm{kg} / \mathrm{m} 3)$, MR is moisture ratio (db), a, b, c, d are the constants. The estimated parameters are given in Table 1.

\section{Cylindrical Food Particulate - Green Bean}

The particle density term used in this paper is defined as the density of the particle including externally connected pores. The green beans in general demonstrated an increased particle density with decreased moisture content, except in the case of L:D ratio of 3:1 particle density decreased at low moisture levels. Particle density of the initial fresh material ranged from $943 \mathrm{~kg} / \mathrm{m} 3(965 \%$ $\mathrm{db}$ moisture) to $964 \mathrm{~kg} / \mathrm{m} 3$ (1035\% db moisture) and final dry material density ranged from $779 \mathrm{~kg} / \mathrm{m} 3$ (3.5 
Table 1. Parameters of particle density variation model $\left[\mathrm{r}_{\rho \mathrm{a}} \mathrm{p}=\mathrm{a}+\mathrm{b} \mathrm{MR}+\mathrm{c} \exp (-\mathrm{d} \mathrm{MR})\right]$ for all materials in fluidised bed drying.

\begin{tabular}{|c|c|c|c|c|c|c|c|c|}
\hline Material & $\begin{array}{l}\mathrm{L}: \mathrm{D} / \mathrm{AR} \\
\quad \text { ratio }\end{array}$ & $\begin{array}{l}\text { Temp } \\
\left({ }^{\circ} \mathrm{C}\right)\end{array}$ & $\mathrm{a}$ & $\mathrm{b}$ & $\mathrm{c}$ & $\mathrm{d}$ & $\mathrm{R}^{2}$ & МAE $\%$ \\
\hline \multirow{3}{*}{ Bean } & $1: 1$ & $\begin{array}{l}30 \\
40 \\
50\end{array}$ & $\begin{array}{l}0.984 \\
0.966 \\
0.995\end{array}$ & $\begin{array}{c}0.017 \\
0.0353 \\
-0.039\end{array}$ & $\begin{array}{c}0.276 \\
0.523 \\
1.04\end{array}$ & $\begin{array}{c}8.74 \\
23.2 \\
408\end{array}$ & $\begin{array}{l}0.91 \\
0.96 \\
0.93\end{array}$ & $\begin{array}{l}2.32 \\
2.17 \\
0.06\end{array}$ \\
\hline & $2: 1$ & $\begin{array}{l}30 \\
40 \\
50\end{array}$ & $\begin{array}{l}0.972 \\
0.827 \\
0.964\end{array}$ & $\begin{array}{c}-0.022 \\
0.110 \\
-0.023\end{array}$ & $\begin{array}{l}0.219 \\
0.369 \\
0.144\end{array}$ & $\begin{array}{l}10.5 \\
8.40 \\
26.6\end{array}$ & $\begin{array}{l}0.93 \\
0.84 \\
0.99\end{array}$ & $\begin{array}{l}1.53 \\
2.44 \\
1.12\end{array}$ \\
\hline & $3: 1$ & $\begin{array}{l}30 \\
40 \\
50\end{array}$ & $\begin{array}{c}0.991 \\
0.935 \\
1.01\end{array}$ & $\begin{array}{c}-0.022 \\
0.042 \\
-0.092\end{array}$ & $\begin{array}{l}-0.137 \\
-0.253 \\
-0.245\end{array}$ & $\begin{array}{l}7.26 \\
15.4 \\
27.4\end{array}$ & $\begin{array}{l}0.88 \\
0.90 \\
0.98\end{array}$ & $\begin{array}{l}0.70 \\
2.64 \\
2.13\end{array}$ \\
\hline \multirow{3}{*}{ Potato } & $1: 1$ & $\begin{array}{l}30 \\
40 \\
50\end{array}$ & $\begin{array}{l}1.16 \\
1.19 \\
1.17\end{array}$ & $\begin{array}{l}-0.126 \\
-0.178 \\
-0.125\end{array}$ & $\begin{array}{c}-1.12 \\
-0.351 \\
-0.272\end{array}$ & $\begin{array}{c}208 \\
97.2 \\
113\end{array}$ & $\begin{array}{l}0.94 \\
0.91 \\
0.81\end{array}$ & $\begin{array}{l}0.96 \\
1.01 \\
1.65\end{array}$ \\
\hline & $2: 1$ & $\begin{array}{l}30 \\
40 \\
50\end{array}$ & $\begin{array}{l}1.14 \\
1.11 \\
1.17\end{array}$ & $\begin{array}{l}-0.108 \\
-0.051 \\
-0.173\end{array}$ & $\begin{array}{c}-0.123 \\
-1.97 \\
-0.467\end{array}$ & $\begin{array}{l}12.8 \\
316 \\
159\end{array}$ & $\begin{array}{l}0.80 \\
0.97 \\
0.80\end{array}$ & $\begin{array}{l}1.12 \\
0.52 \\
1.53\end{array}$ \\
\hline & $3: 1$ & $\begin{array}{l}30 \\
40 \\
50\end{array}$ & $\begin{array}{l}1.14 \\
1.14 \\
1.12\end{array}$ & $\begin{array}{l}-0.099 \\
-0.086 \\
-0.108\end{array}$ & $\begin{array}{l}-0.240 \\
-0.252 \\
-0.412\end{array}$ & $\begin{array}{l}64.3 \\
75.8 \\
236\end{array}$ & $\begin{array}{l}0.93 \\
0.81 \\
0.90\end{array}$ & $\begin{array}{l}0.76 \\
1.15 \\
0.91\end{array}$ \\
\hline Peas & & $\begin{array}{l}30 \\
40 \\
50\end{array}$ & $\begin{array}{l}1.17 \\
1.13 \\
1.10\end{array}$ & $\begin{array}{l}-0.166 \\
-0.133 \\
-0.098\end{array}$ & $\begin{array}{c}0.081 \\
0.136 \\
4.89\end{array}$ & $\begin{array}{l}13.7 \\
15.3 \\
142\end{array}$ & $\begin{array}{l}0.99 \\
0.88 \\
0.89\end{array}$ & $\begin{array}{l}1.24 \\
1.84 \\
1.59\end{array}$ \\
\hline
\end{tabular}

$\mathrm{db}$ moisture) to $1393 \mathrm{~kg} / \mathrm{m} 3$ (4.1\% db moisture). Particle density variation with moisture ratio for beans during fluidized bed drying was correlated to a non-linear model similar to the model suggested by Lozano et al. (1983) for vegetables and fruits. Moisture ratio was selected instead of moisture to avoid effects due to the natural variation in initial moisture content. Figure 3 shows particle density variation of beans at $30^{\circ} \mathrm{C}$.

These parameters were tested for their statistical significance. It was found that only the $b$ value was significantly different $(\mathrm{p}<0.05)$ for different drying temperatures for each size. The value $b$ represents the rate of change of particle density in the linear region, and it is dependent on the temperature. The constant c of the exponential part of the equation appears to have a decreasing trend, decreasing as the L: D ratio increases (Table 1). This indicates that towards the end of drying, the L: D ratio affects the particulate density. As the L: D ratio increased the value of $c$ decreased from positive to negative. A positive $\mathrm{c}$ means an increase in particle density and negative c means a decrease in particle density. It can therefore be concluded that $\mathrm{c}$ is a measure of internal porosity or internal collapse. The parameter $\mathrm{d}$ is a measure of rate change of density in the

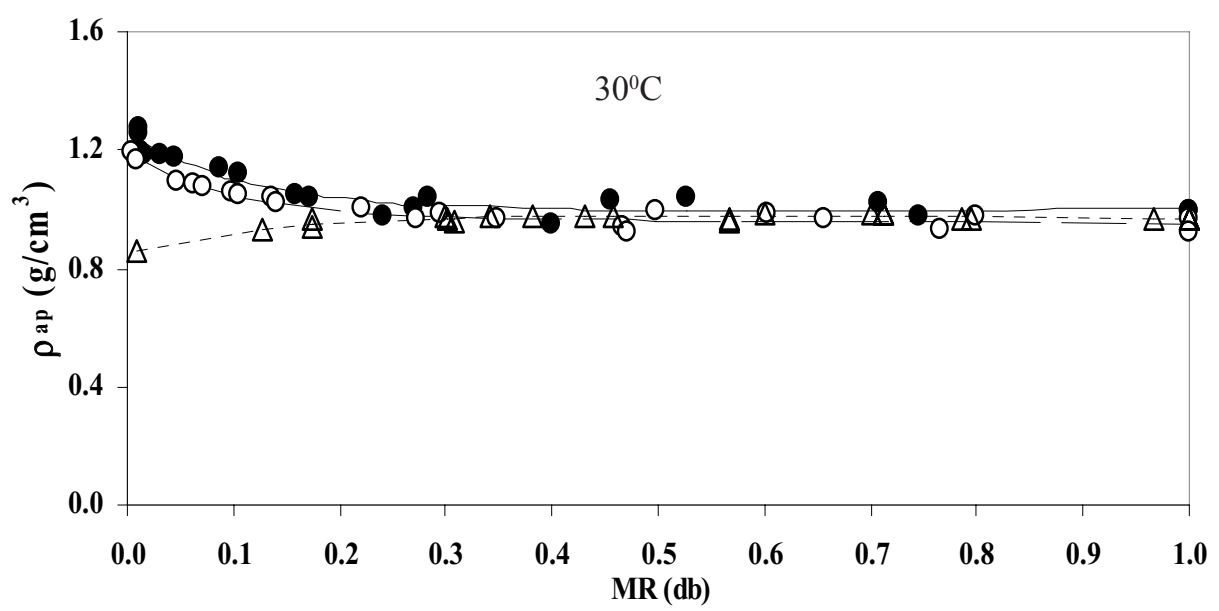

Figure 3. Particle density variation of beans during fluidised bed drying. ( experimental L:D =1:1 - model L:D =1:1); (o experimental L:D=2:1 -- model L:D=2:1); $(\Delta$ experimental L:D =3:1 ... model L:D =3:1). 


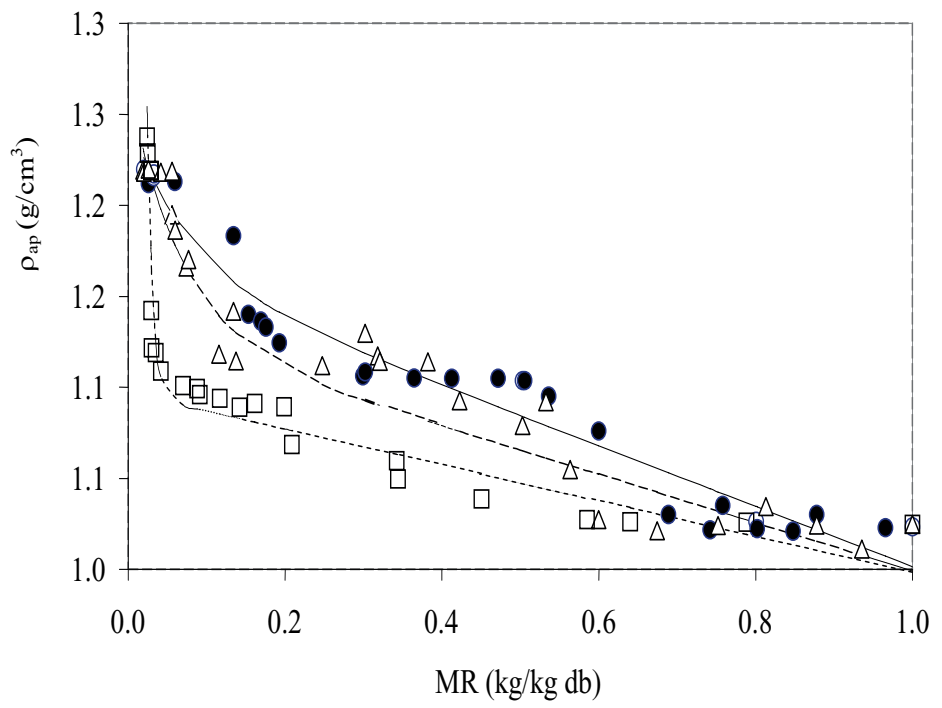

Figure 4. Particle density variation of peas during fluidised bed drying. $\left(\bullet\right.$ experimental $\left.30^{\circ} \mathrm{C}-\operatorname{model} 30^{\circ} \mathrm{C}\right) ;\left(\Delta\right.$ experimental $40^{\circ} \mathrm{C}$ -- model $\left.40^{\circ} \mathrm{C}\right)$; ( $\square$ experimental $50^{\circ} \mathrm{C} \ldots$ model $50^{\circ} \mathrm{C}$ ).

non-linear region experienced at low moisture contents. The negative $\mathrm{c}$ value found for $\mathrm{L}: \mathrm{D}=3: 1$ indicated that internal porosity was increased. This may be due to the long axial dimension, which facilitated closing of ends and trapping of air inside voids. Particle density therefore decreased. For $\mathrm{L}: \mathrm{D}=2: 1$ and 1:1 it was found that particle density increased at lower moisture contents. Some form of collapse of the structure must have contributed to this increase. For L: $\mathrm{D}=1: 1$ and $\mathrm{L}: \mathrm{D}=2: 1$, the general trend of particle density behavior was similar at $30^{\circ} \mathrm{C}$ and $40^{\circ} \mathrm{C}$. However, at $30^{\circ} \mathrm{C}$, the magnitude of increase was lower than at other temperatures. In the case of $\mathrm{L}: \mathrm{D}=3: 1$, results were similar at all temperatures.

\section{Parallelepiped Food Particulate - Potato}

Particle density variation of potato during fluidised bed drying was correlated to a non-linear model with a moisture ratio similar to the model suggested by Lozano et al. (1983) for vegetables and fruits. The particle density of potato increases with decreasing moisture content. However, once the product neared its final fixed volume and shape, the reduced shrinkage resulted in increased particle density.

The particle density behaviour of potatoes with respect to moisture removal was similar to the particle density behaviour of beans. Similar behaviour was observed for all aspect ratios at all temperatures. Materials with aspect ratio 1:1 always tended to have a higher particle density than materials at other aspect ratios. It appeared that aspect ratio $2: 1$ showed lower particle density behaviour at $30^{\circ} \mathrm{C}$, and $40^{\circ} \mathrm{C}$. However, an aspect ratio $3: 1$ showed decreased magnitude at $50^{\circ} \mathrm{C}$ and an increased magnitude at $40^{\circ} \mathrm{C}$. The $b$ value was significantly different $(p<0.05)$ with temperature for each size. The value $b$ represents the rate of change of particle density in the linear region.

\section{Spherical Food Particulate - Green Peas}

Particle density variation of peas during fluidized bed drying is shown in Fig 4 for different drying temperatures. The particle density of peas increased with decreasing moisture content until moisture was $0.15 \mathrm{~kg} / \mathrm{kg} \mathrm{db}$ and the rate of increase decreased with the drying temperature in the linear region. Below this moisture value, there was a higher rate of increase of particle density at higher temperatures, so that all treatments resulted in similar final particle density. At lower moisture values, even though the structure may be tougher due to removal of moisture, it was not enough to compensate for the effect of increased internal void (porosity) and increase in temperature of the product. This resulted in collapse of the structure. This behaviour was similar to the behaviour studied for various other fruits and vegetables by Lozano et al. (1983). A similar model characterising the change in particle density with change in moisture during drying for peas, was fitted by Medeiros and Sereno (1994). These results are similar to the earllier published reports. The parameters of the model equation given in Table 1 were tested for their significance. It was found that the $\mathrm{b}$ and $\mathrm{c}$ values are significantly different $(p<0.05)$ with temperature for each size. The value $b$ represents the rate of change of particle density in the linear region.

\section{Bulk Density}

The variation of bulk density of the bed of particulates at different drying temperatures and L: D ratios were correlated to moisture, using a polynomial quadratic equation of the form:

$$
\rho_{b}=A+B M R+C M R^{2}
$$


Table 2. Parameters of bulk density variation models of materials $\left(r_{p} b=A+B M R+C M^{R} 2\right)$ in fluidised bed drying.

\begin{tabular}{|c|c|c|c|c|c|c|c|}
\hline Material & $\mathrm{L}: \mathrm{D} / \mathrm{AR}$ ratio & Temp $\left({ }^{\circ} \mathrm{C}\right)$ & A & B & $\mathrm{C}$ & $\mathrm{R}^{2}$ & MAE\% \\
\hline \multirow{9}{*}{ Bean } & \multirow{3}{*}{$1: 1$} & 30 & 268.61 & 598.07 & -370.37 & 0.97 & 3.35 \\
\hline & & 40 & 255.70 & 747.27 & -512.50 & 0.96 & 3.96 \\
\hline & & 50 & 251.06 & 682.88 & -426.24 & 0.97 & 3.34 \\
\hline & \multirow{3}{*}{$2: 1$} & 30 & 225.87 & 621.46 & -397.78 & 0.87 & 9.83 \\
\hline & & 40 & 213.11 & 677.39 & -453.97 & 0.86 & 9.33 \\
\hline & & 50 & 218.79 & 656.87 & -426.37 & 0.91 & 9.06 \\
\hline & \multirow{3}{*}{$3: 1$} & 30 & 233.46 & 537.77 & -321.85 & 0.82 & 6.61 \\
\hline & & 40 & 223.73 & 620.95 & -405.79 & 0.86 & 9.65 \\
\hline & & 50 & 198.15 & 712.02 & -473.55 & 0.96 & 6.53 \\
\hline \multirow{9}{*}{ Potato } & \multirow{3}{*}{$1: 1$} & 30 & 384.35 & 587.43 & -376.17 & 0.94 & 3.28 \\
\hline & & 40 & 380.60 & 630.16 & -431.32 & 0.97 & 2.60 \\
\hline & & 50 & 353.96 & 798.24 & -568.80 & 0.99 & 1.59 \\
\hline & \multirow{3}{*}{$2: 1$} & 30 & 304.68 & 633.78 & -380.91 & 0.97 & 3.27 \\
\hline & & 40 & 314.59 & 638.66 & -394.40 & 0.95 & 4.58 \\
\hline & & 50 & 314.03 & 640.37 & -391.32 & 0.97 & 3.47 \\
\hline & \multirow{3}{*}{$3: 1$} & 30 & 263.10 & 623.35 & -363.65 & 0.97 & 2.76 \\
\hline & & 40 & 236.71 & 458.35 & -162.42 & 0.97 & 3.69 \\
\hline & & 50 & 257.78 & 504.44 & -235.45 & 0.99 & 2.24 \\
\hline \multirow{3}{*}{ Peas } & & 30 & 687.09 & -23.835 & -98.726 & 0.85 & 2.21 \\
\hline & & 40 & 659.93 & 39.805 & -131.760 & 0.81 & 1.98 \\
\hline & & 50 & 508.93 & 446.85 & -407.826 & 0.80 & 2.40 \\
\hline
\end{tabular}

where, $\mathrm{A}, \mathrm{B}, \mathrm{C}$ are constants, $\mathrm{MR}$ is moisture ratio $(\mathrm{kg} / \mathrm{kg}$ $\mathrm{db}), \rho \mathrm{b}$ is bulk density $(\mathrm{kg} / \mathrm{m} 3)$. The estimated parameters of the model are presented in Table 2. The General Linear Modelling (GLM) regression procedure (SAS, 1985) was used to estimate the parameters in Table 2 for all the materials.

\section{Cylindrical Food Particulate - Green Bean}

The bulk density of the fresh beans for all L: D ratios at all temperatures reached a maximum early in the drying period, and then dropped as the material dried further (Figure 5). The bulk density of dried material during the later stages of drying was much lower than that of the fresh material. During the early stages of drying, there was uniform shrinkage without any irregularities on the surface. This contributed to the increase in bulk density as the particles could more easily pack together. However, further drying resulted in a wrinkled surface, and twisting and deformation of the shape, increasing the interparticulate airspace. This reduced the density of the bulk material. None of the parameters given in Table 2 were significantly different $(\mathrm{p}<0.05)$ with temperature or size.

\section{Parallelepiped Food Particulate - Potato}

The variation of bulk density of different aspect ratios at different temperatures were correlated to moisture using a polynomial quadratic equation as in the case of beans (Table 2). None of the parameters are significantly different $(p>0.05)$ with the temperature. The values of $A$ and $C$ are significantly different $(\mathrm{p}<0.05)$ with the aspect ratio. The

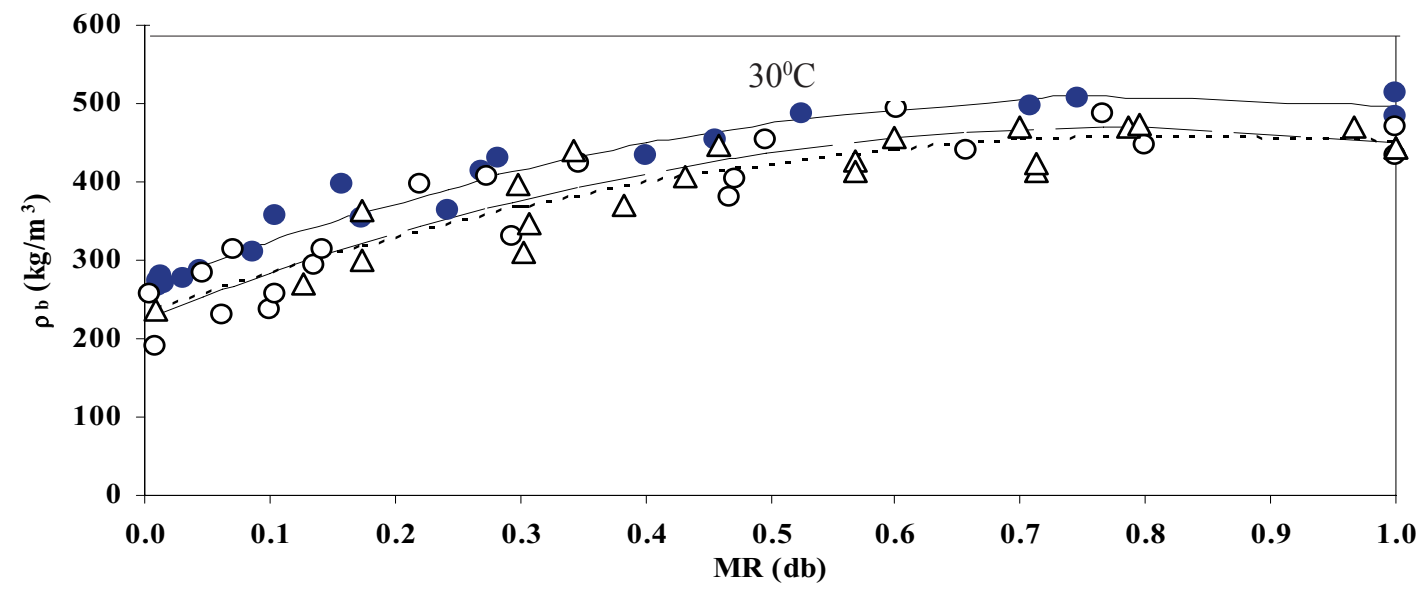

Figure 5. Bulk density variation of beans during fluidised bed drying. ( $\bullet$ experimental L:D =1:1 - model L:D =1:1); (o experimental $\mathrm{L}: \mathrm{D}=2: 1$-- model L:D=2:1); $(\Delta$ experimental L:D =3:1 ... model L:D =3:1). 


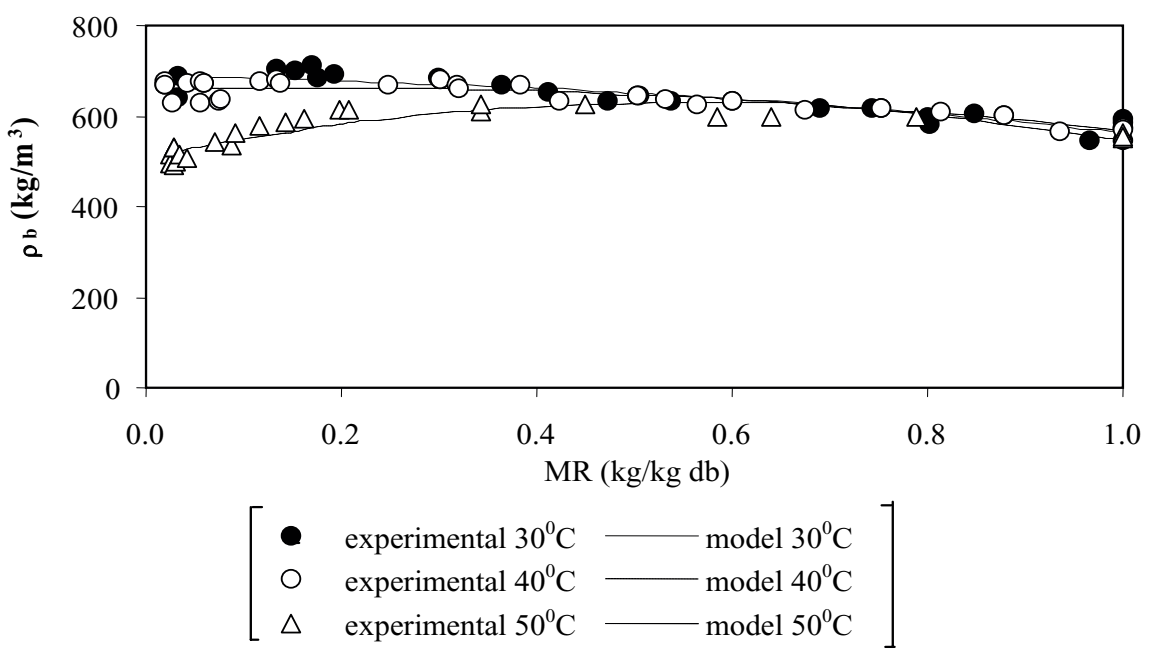

Figure 6. Bulk density variation of peas during fluidised bed drying.

bulk density variation of the fresh potato with the moisture removal for all aspect ratios at all temperatures showed a similar trend to that of beans.

\section{Spherical Food Particulate - Green Peas}

Figure 6 shows the bulk density variation of peas during fluidised bed drying at different temperatures. The experimental data for bulk density were correlated with moisture ratio with quadratic equations for different temperatures and are presented in Table 2. The bulk density of peas increased to a maximum and again reduced as drying proceeded. The correlation coefficients of the equations in Table 2 were poor. However, MAE\% indicated that they are sufficient to characterise the trend in change in bulk density with respect to moisture removal. A similar trend was observed for green beans with length: diameter ratio 1:1 during drying. Drying peas at $50^{\circ} \mathrm{C}$ resulted in a less dense product. The reduced shrinkage of peas dried at $50^{\circ} \mathrm{C}$ would have been a major factor in this effect.

\section{Generalized Models}

\section{Particle density}

The generalized form of Particle Density variation of all three materials (beans, potato and peas) showed very poor correlation coefficients among size and temperature.

\section{Bulk density}

As none of the parameters given in Table 2 were significantly different $(\mathrm{p}<0.05)$ with temperature and size for beans, for generalization purposes, a single quadratic equation for the bulk density can be assumed. The general linear modeling (GLM) in SAS was used to obtain the generalised equation. The generalized equation can be written as:

$$
\begin{gathered}
\rho_{b}=235.4078+606.0321 \mathrm{MR}-382.9058 \mathrm{MR}^{2} \\
\left(\mathrm{R}^{2}=0.86, \mathrm{MAE} \%=9.33\right)
\end{gathered}
$$

For generalisation purposes, it was assumed that A and $\mathrm{C}$ parameters are linearly correlated with aspect ratio. A quadratic equation for the bulk density could be written including aspect ratio. The generalised equation can be written as:

$$
\begin{aligned}
& \rho_{\mathrm{b}}=440.1465+606.1219 \mathrm{MR}-63.9437 \mathrm{AR}-423.2582 \mathrm{MR}^{2} \\
& +31.4523 \mathrm{MR}^{2} \mathrm{AR}\left(\mathrm{R}^{2}=0.97, \mathrm{MAE} \%=4.28\right)
\end{aligned}
$$

The generalized form for the bulk density variation among temperatures of peas was evaluated. However, it also has a very poor correlation coefficient.

\section{Conclusion}

In this study a correlation between apparent density and bulk density with moisture content was observed. For beans, particle density tended to increase for the whole range except for $\mathrm{L}: \mathrm{D}=3: 1$ at all temperatures. For $\mathrm{L}: \mathrm{D}=$ $1: 1$ and 2:1. Some form of collapse may have contributed for the increased in particle density at low moisture values. Beans with L: $\mathrm{D}=3: 1$ showed a decreased particle density due to increased internal porosity at low moisture contents. Potato particle density reached a maximum value and decreased at low moisture for all aspect ratios. In the case of peas at all temperatures, particle density was increased with the decreased moisture content until moisture was 0.15 $\mathrm{kg} / \mathrm{kg} \mathrm{db}$. Below this moisture content it was observed that the rate of increase of particle density of peas was higher at higher drying temperatures. Bulk density variation of beans, peas and potato with moisture ratio was correlated to similar quadratic models. The models could be further improved by considering material particle (solid) density to investigate effects of temperature and particle shapes on porosity development during drying.

\section{Nomenclature}

$\mathrm{a}, \mathrm{b}, \mathrm{c}, \mathrm{d}$ constants

A, B, C constants 
L length (m)

D diameter $(\mathrm{m})$

$\mathrm{A}^{\mathrm{R}} \quad$ aspect ratio

$\rho \quad$ density $(\mathrm{kg} / \mathrm{m} 3)$

MR moisture ratio $(\mathrm{db})$

\section{Suffixes}

a apparent

b bulk

\section{References}

AOAC. 1995. Official Methods of Analysis, 16th edition. Association of Official Analytical Chemists, Washington, DC.

Fusco, A. J., J.R. Avanza, R.J. Aguerre and J.F. Gabritto. 1991. A diffusion model for drying with volume change. Drying Technology 9:397-417.

Gibert, H., J.L. Baxerres and H. Kim. 1980. Blanching time in fluidized beds. In: Food Process Engineering 1: Food Processing Systems. P. Linko, Y. Malkki, J. Olkku and J. Larinkari (Editors), 75-85. Applied Science Publishers, London.

Giner, S.A. and A. Calvelo. 1987. Modelling of wheat drying in fluidized beds. Journal of Food Science 52: 1358-1363.

Karel, M. 1991. Physical structure and quality of dehydrated food. In: Drying '91. A.S. Mujumdar and I. Filkova (Editors), 26-35. Elsevier Science Publishers, Amsterdam.

Krokida, M.K. and Z.B. Maroulis. 1997. Effect of drying method on shrinkage and porosity. Drying Technology 15:2441-2458

Lozano, J.E., E. Rotstein and M.J. Urbician. 1983. Shrinkage, porosity and bulk density of food stuffs at changing moisture contents. Journal of Food Science 48:1497-1502.

Madamba, P.S., R.H. Driscoll and K.A. 1994a. Shrinkage, density and porosity of garlic during drying. Journal of Food Engineering 23:309-319.
Madamba, P.S., R.H. Driscoll and K.A. Buckle. 1994b. Bulk density, porosity and resistance to airflow of garlic slices. Drying Technology 12(4):937-954.

Medeiros, G.L. and A.M. Sereno. 1994. Physical and transport properties of peas during warm air drying. Journal of Food Engineering 21:355-363.

Rahman, S. and R.H. Driscoll. 1994. Density of fresh and frozen seafood. Journal of Food Engineering 17:121140.

Rahman, S. and P.L. Potluri. 1990. Shrinkage and density of squid flesh during drying. Journal of Food Engineering 12:133-143

Ratti, C. 1994. Shrinkage during drying of food stuffs. Journal of Food Engineering 23:91-105.

Senadeera, W., B.R. Bhandari, G. Young and B. Wijesinghe. 1998. Change of physical properties of green beans during drying and its influence on fluidization. In: Drying'98, Volume B-Proceedings of the 11th International Drying Symposium, Halkidiki, Greece,. C.B. Akitidis, D. Marinos-Kouris and G.D. Saravakos (Editors), 1139-1146, Ziti Editions (Pub.), Thessaloniki, Greece.

SAS. 1985. User's Guide: Statistics, 5th edition. SAS Institute Inc., Cary, NC.

Senadeera, W., B.R. Bhandari, G. Young and B. Wijesinghe. 1998. Fluidization behaviour of cylindrical green beans during batch fluidized bed drying. Tropical Agricultural Research 10:192-202.

Wang, N. and J.G. Brennan. 1995. Changes in structure, density and porosity of potato during dehydration. Journal of Food Engineering 24:61-76.

Zogzas, N.P., Z.B. Maroulis and D. Marinos-Kouris. 1994. Densities, shrinkage and porosity of some vegetables during air drying. Drying Technology 12:1653-1666.

Received: November 2007

Accepted: April 2008 